\title{
Mild to Moderate Early Exercise Promotes Recovery from Cerebral Ischemia in Rats
}

\author{
Shi-Uk Lee, Dae-Yul Kim, Sung-Hye Park, Deok-Hyung Choi, \\ Hee-Won Park, Tai Ryoon Han
}

\begin{abstract}
Objective: We examined the effects of various exercise intensities on recovery from middle cerebral artery occlusion (MCAO) in rats. Methods: First, we administered a 120-minute left MCAO to male Sprague-Dawley rats and randomly assigned them to one of four groups: no exercise (Group 1), mild exercise (Group 2), moderate exercise (Group 3), and severe exercise (Group 4). Then, we trained the rats for $30 \mathrm{~min}$ per day for one week or two weeks. We used a five-point neurological evaluation scale to measure neurological deficits 1-day, 4-days, 7-days, 10-days and 14-days after MCAO and measured infarct volume by use of 2\% 2,3,4triphenyltetrazolium chloride in exercised brains. We also performed immunohistochemistry analysis of the brain to observe reactive astrocytosis at the peri-infarct region. Results: Neurological examination indicated that Group 2 and 3 recovered better than Group 1 after one week and two weeks $(\mathrm{p}<0.05)$. Moreover, Group 2 and 3 had reduced brain infarct volume compared with Group 1 after one week $(p<0.05)$. There were no significant differences between Group 4 and Group 1 . The thickness of the peri-infarct astrocytosis was significantly reduced in Group 4 relative to Group 1 after one week. There was a significant negative correlation between the extent of reactive astrocytosis and neurological recovery $(r=-0.648, \mathrm{p}<0.01)$. Conclusion: This study demonstrates that mild to moderate exercise that begins soon after induced cerebral ischemia promotes recovery and that astrocytes may have an important role in the recovery process.
\end{abstract}

RÉSUMÉ: L'exercice de léger à modéré favorise la récupération de l'ischémie cérébrale chez le rat. Objectif : Nous avons étudié les effets de différentes intensités d'exercice sur la récupération après une occlusion de l'artère cérébrale moyenne (OACM) chez des rats. Méthodes : Nous avons d'abord procédé à une OACM gauche de 120 minutes chez des rats Sprague-Dawley mâles et nous les avons répartis au hasard entre quatre groupes : aucun exercice (groupe 1); exercice léger (groupe 2); exercice modéré (groupe 3) et exercice intensif (groupe 4). Nous leur avons ensuite fait subir un entraînement de 30 minutes par jour pendant 1 ou 2 semaines. Nous avons utilisé une échelle d'évaluation neurologique en cinq points pour mesurer les déficits neurologiques $1,4,7,10$ et 14 jours après l'OACM et nous avons mesuré le volume de l'infarctus au moyen du chlorure de 2,3,4triphényltétrazolium à $2 \%$. Nous avons procédé à des analyses immunohistochimiques du cerveau pour étudier l'astrocytose réactionnelle dans la région entourant l'infarctus. Résultats : L'examen neurologique a montré que les groupes 2 et 3 avaient mieux récupéré que le groupe 1 après une semaine et deux semaines $(\mathrm{p}<0,05)$. De plus, chez les rats des groupes 2 et 3 , le volume de l'infarctus était moindre que celui des rats du groupe 1 après une semaine $(\mathrm{p}<0,05)$. Il n'y avait pas de différences significatives entre le groupe 4 et le groupe 1 . L'épaisseur de l'astrocytose dans la zone entourant l'infarctus était significativement moindre dans le groupe 4 par rapport au groupe 1 après une semaine. Il existait une corrélation négative significative entre l'importance de l'astrocytose et la récupération neurologique $(r=-0,648 ;(p<0,01)$. Conclusion : Cette étude démontre que l'exercice d'intensité légère à modérée, commencé tôt après une ischémie cérébrale provoquée, favorise la récupération et qu'il est possible que les astrocytes jouent un rôle important dans le processus de récupération.

Can. J. Neurol. Sci. 2009; 36: 443-449

Neurological recovery begins soon after the onset of cerebral ischemia or hemorrhage. Despite this, about $73 \%$ of stroke patients suffer from severe neurological disorders. ${ }^{1}$ Thus, it is essential to use proactive rehabilitation to minimize the longterm disabilities of stroke patients. It is well established that rehabilitation should be conducted as early as possible after the onset of stroke, but a standardized program has not yet been established. ${ }^{2}$

Rehabilitation from stroke has focused mainly on functional recovery through exercise. Several animal models of cerebral ischemia have shown the benefits of exercise..$^{3-5}$ In addition,
From the Department of Rehabilitation Medicine (SUL), Seoul National University Boramae Hospital, Sindaebang-Dong, Dongjak-Gu, Seoul; Department of Rehabilitation Medicine (DYK), University of Ulsan College of Medicine, Seoul Asan Medical Center, Songpa-Gu, Seoul; Department of Pathology (SHP), Department of Rehabilitation Medicine (DHC, HWP, TRH), Chongro-gu, Seoul, Seoul National University Hospital, Seoul, South Korea.

Received October 27, 2008. Final Revisions Submitted March 2, 2009. Correspondence to: Dae-Yul Kim, Department of Rehabilitation Medicine, University of Ulsan College of Medicine Seoul Asan Medical Center, 388-1, Pungnap-2dong, Songpa-Gu, Seoul, 138-736, South Korea. 
clinical studies have reported that treadmill gait training after the onset of stroke effectively promoted recovery. ${ }^{6,7}$ The results of rehabilitation therapy for stroke depend on the timing and intensity of the therapy. Some reports showed that daily activities conducted within 24 hours of cerebral ischemia improved functional outcome of animals with no induction of cerebral injury. ${ }^{8,9}$ However, another report insisted that early intense exercises that was performed soon after cerebral ischemia had negative effects on neurological recovery. ${ }^{10,11}$ By contrast, a recent study demonstrated that animals that performed treadmill exercise 24 hours after the onset of cerebral ischemia showed better neurological recovery than animals that did not exercise. ${ }^{12}$ Another study showed that animals that exercised within 24 hours of cerebral ischemia showed functional recovery with no injury to cerebral tissues when compared with the group that exercised seven days after cerebral ischemia. ${ }^{13}$

Based on these experimental reports, it seems that early exercise after stroke maximizes recovery, but that excessive exercise can delay functional recovery. Thus, therapeutic exercise soon after a stroke requires determination of the appropriate exercise intensity. Unfortunately, few studies have focused on determination of appropriate exercise intensity.

The purpose of this study was to examine the effect of a twoweek duration of three different levels of exercise (mild, moderate and severe) on recovery of rats from experimentally induced ischemic brain damage. This study also aims to investigate possible associations between neurological recovery and astrocyte reactions. Our aim is to build a foundation for the determination of the optimal exercise intensity that promotes maximal functional recovery from stroke.

\section{Methods}

\section{Animals and Middle cerebral artery occlusion procedures}

We used adult male Sprague-Dawley rats (Charles River, Wilmington, MA, USA) that weighed 250-320g. Rats were adapted for one week to our laboratory environment: temperature $22^{\circ} \mathrm{C}$, shading adjusted every $12 \mathrm{~h}$, food and water administered ad libitum. Animal care and surgical procedures were in accordance with the guidelines of the Administrative Panel on Laboratory Animal Care of the Seoul National University Hospital Clinical Research Institute.

A total of 115 rats were used for experiment in this study. Ischemic injury was induced as described by Longa et al, ${ }^{14}$ briefly described below. Intra-abdominal anesthesia was performed using $1 \%$ ketamine $(30 \mathrm{mg} / \mathrm{kg})$ and xylazine hydrochloride $(4 \mathrm{mg} / \mathrm{kg})$. Rectal temperature was maintained at $37^{\circ} \mathrm{C}$ with a circulating heating pad. A filament (4-0 nylon suture with a blunted tip) was inserted into the left common carotid artery via an arteriotomy. The filament was then passed up the lumen of the internal carotid artery into the intracranial circulation and lodged in the narrow proximal anterior cerebral artery, thus blocking the middle cerebral artery (MCA) at its origin. Animals were re-anesthetized two hours after middle cerebral artery occlusion (MCAO), and reperfusion was established by withdrawal of the filament. After animals were awakened from anesthesia, they were given food and water $a d$ libitum.

Twenty-four hours after the operation, we measured motor behavior to determine the extent of cerebral ischemic injury.
Animals that scored 9-13 points on a motor behavior index 15 were included in our experimental group; animals that scored out of this range were excluded. Ischemic animals were randomly assigned into one of the following groups: Group 1, natural recovery with no exercise $(n=40)$; Group 2, mild intensity exercise $(n=25)$; Group 3, moderate intensity exercise $(n=25)$; Group 4, severe intensity exercise $(n=25)$.

\section{Treadmill training protocol}

For all experiments, we used a treadmill (Columbus instrument, USA) designed specially for rats. Twenty-four hours after induction of cerebral ischemic injury, each animal was subjected to a 15-minute warmup period on the treadmill at a rate of $5 \mathrm{~m} / \mathrm{min}$. Then, we determined the exercise 'velocity over maximum intensity'- the velocity at which animals cannot run any longer due to fatigue (no more than three minutes after the onset of exercise). Once this was determined, we subjected Group 1 to no exercise; Group 2 to exercise at $30 \%$ of the maximum velocity; Group 3 to exercise at $60 \%$ of the maximum velocity; and Group 4 to exercise at $80 \%$ of the maximum velocity. First, each of the three groups (excluding control, Group 1) performed a 15-min warmup period at $10 \%$ load of maximum intensity. Then, the groups performed a 30-minute exercise period at the target exercise intensity. Each exercise period began within 24 hours of ischemic injury and was performed for 30 minutes per day for 7 or 14 days. Treadmill exercise in all rats was performed during constant daytime.

\section{Neurological examinations}

On the 1st, 4th, 7th, 10th, and 14th days after cerebral ischemia, neurological examinations were conducted by a researcher who was blinded to the identity of the exercise groups. To reduce daily variations in the course of measurement, all examinations were conducted at night using a 5-point scale, as described by Menzies et $\mathrm{al}^{16}$ The scale is defined as follows: 0 points, no apparent deficits; 1 point, right forelimb flexion; 2 points, decreased grip of the right forelimb when the tale is pulled; 3 points, spontaneous movement in all directions, but right circling when the tail is pulled; 4 points, spontaneous right circling.

\section{Quantitative analysis of infarct volume}

For animal sacrifice, we administered 1\% ketamine (30 $\mathrm{mg} / \mathrm{kg}$ ) and xylazine hydrochloride $(4 \mathrm{mg} / \mathrm{kg}$ ) into the abdomen and then removed the brain. The brains were isolated $2 \mathrm{~mm}$ from the frontal region on coronal section and were then subdivided into six sections using a tissue slicer. Each section was immersed in 2\% 2,3,4-triphenyl-tetrazolium chloride (TTC) solution at $37^{\circ} \mathrm{C}$ for 30 minutes, then submersed in $10 \%$ phosphate-buffered formalin solution at $4^{\circ} \mathrm{C}$. To determine the volume of regions affected by cerebral infarctions, we scanned each section using a charge-coupled device (CCD) camera. For image analysis, we used the Scion Image Program (Scion Image Beta 4.02 for windows, Scion Corp., USA) and determined the volume of injured tissues by considering the unstained region as the region that was affected by cerebral infarction. For the group sacrificed 24 hours after cerebral ischemia, cerebral edema on the affected hemisphere may have had an effect on regions affected by a 


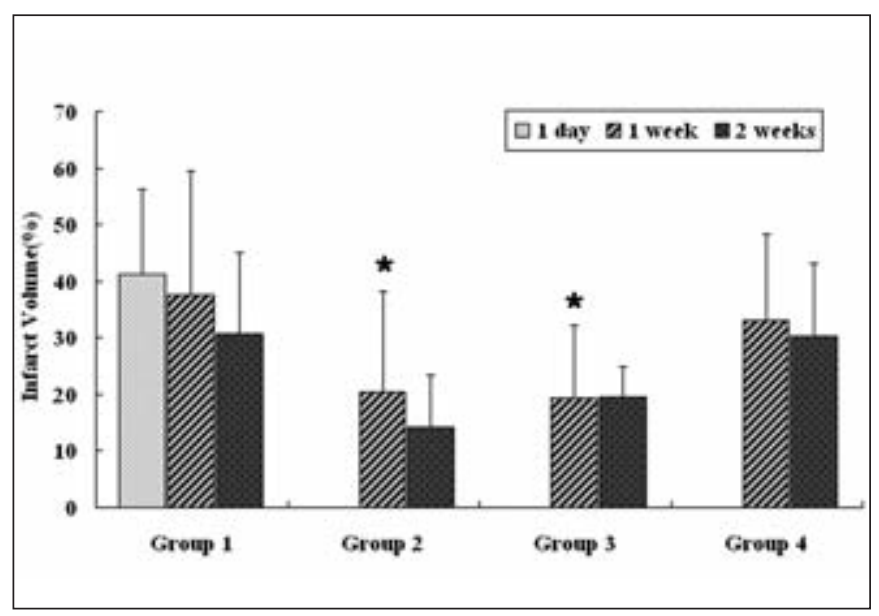

Figure 1: Infarct volume following MCAO. *Significantly different $(p<0.05)$ from Group 1 at one week after MCAO.

cerebral infarction; therefore, we used a calibrated injury volume for measurement. This calibrated value was calculated by subtracting the volume of regions affected by cerebral infarction from the volume of the affected cerebral hemisphere, then subtracting this value from the volume of the unaffected cerebral hemisphere ${ }^{17}$ Animals sacrificed 7 and 14 days after cerebral ischemia showed no signs of cerebral edema, so the volume of a region injured by cerebral ischemia was determined only from the volume using that of cerebral infarction region. The volume of a region affected by cerebral infarction was expressed as percentage $(\%)$ of the volume of the unaffected cerebral hemisphere.

\section{Immunohistochemistry}

The excised brain was immersed in $10 \%$ phosphate buffered formalin solution at $4^{\circ} \mathrm{C}$ for 12 hours, then stained in paraffin with a procedures used to keep tissues stable. First, paraffin blocks were sliced into $2-3 \mu \mathrm{m}$-thick sections and the paraffin was removed with xylene. Next, sections were hydrated stepwise in ethyl alcohol and LSAB (labelled streptavidin biotin method; Dako, Denmark) for immunohistochemical staining. The primary antibody was glial fibrillary acid protein (GFAP, 1:100, Dako, Denmark) and was used to observe glial cell differentiation. The neuronal nuclei antibody (NeuN, 1:200, Chemicon, CA, USA) was used to monitor injury of nerve cells. To restore the antigen, block sections were heated in a pressure pan containing citrate buffer or were microwaved for $20 \mathrm{~min}$ after hydration. The primary antibodies were incubated for 1 hour at room temperature and then cultured in the freezer for 12 hours. The secondary antibodies (coupled with biotin; prediluted, Immunotech, Marseille, France) were added, followed by streptavidin coupled with horseradish peroxidase. Then, DAB (a chromogen; 3,3-diaminobenzidine tetrachloride) was added and Mayer's hematoxylin was used for contrast staining. The completely processed cerebral tissue was fixed on a gelatine-coated slide and a cover glass was placed on the slide under a vacuum for light microscopy analysis. The regions where there was a GFAP-positive reaction around the lesion affected by cerebral infarction were observed to measure the thickness of reactive astrocyte layer around lesion of cerebral infarction using a calibrated ruler on three random microscopic fields $(\mathrm{x} 40)$. The values obtained from three measurements were averaged.

\section{Statistical analysis}

All values are expressed as mean \pm standard deviation. Intergroup statistical data were analyzed with SPSS 14.0 for Windows (SPSS, Chicago, IL, USA). The volume of ischemic injury, values of the neurological examination and the thickness of astrocyte layers, as determined by immunohistochemical staining, was compared using Kruskal-Wallis analysis and between-group differences were compared respectively using the Mann-Whitney U test. Spearman's coefficient of correlation was used to express the correlations between reactive astrocyte layer thickness and score on the neurological test.

\section{RESULTS}

The total of 109 rats with MCAO $(n=36$ in Group $1, n=23$ in Group 2, $\mathrm{n}=25$ in Group 3, $\mathrm{n}=25$ in Group 4) completed the experimental protocols. The four rats that died during experimental procedures and two rats that showed scoring out of 9-13 points on motor behavior index on postoperative day 1 were excluded. The groups under exercise in 24 hours after cerebral ischemic injury scored the following mean values of velocity over maximum intensity: Maximum exercise intensity in Group 2 averaged $23.0 \pm 6.0 \mathrm{~m} / \mathrm{min}$, maximum exercise intensity in Group 3 averaged $22.3 \pm 5.1 \mathrm{~m} / \mathrm{min}$, and maximum exercise intensity in Group 4 averaged $20.9 \pm 5.7 \mathrm{~m} / \mathrm{min}$, but there was not any statistically significant difference found between groups.

Neurological examinations performed one day and four days after cerebral ischemia indicated no significant differences among the four groups. However, seven days after cerebral ischemia, we noted significant improvements in Group 2 and Group 3 relative to Group 1. In addition, 14 days after cerebral ischemia, Group 2 and Group 3 showed additional improvements relative to Group 1. Group 4 showed a modest improvement compared with Group 1, but this was not statistically significant at the 0.05 level (Table 1).

Gross examination of brain slices by TTC staining indicated cerebral infarction around the MCA region, including the cerebral cortex and basal ganglia. Compared with Group 1, Groups 2 and 3 had significantly less infarct volume one week after cerebral ischemia. However, there was no significant difference between Group 1 and Group 4. (Table 2, Figure 1).

We readily observed brain regions with higher GFAP reactivity around cerebral ischemic region (Figure 2). All groups showed lower or no NeuN immune reactivity around regions affected by cerebral infarction. To determine the effect of exercise intensity on the activity of astrocytes in regions affected by cerebral infarction, we measured the thickness of reactive astrocyte layers that surrounded regions where there was cerebral infarction. Seven days after cerebral ischemia, there was no significant differences between Groups 2 or 3 and Group 1; however, Group 4 had a significantly reduced astrocyte thickness relative to Group $1(\mathrm{p}<0.05)$. However, all Groups showed no significant differences in thickness two weeks after cerebral ischemia (Table 2, Figure 3). 


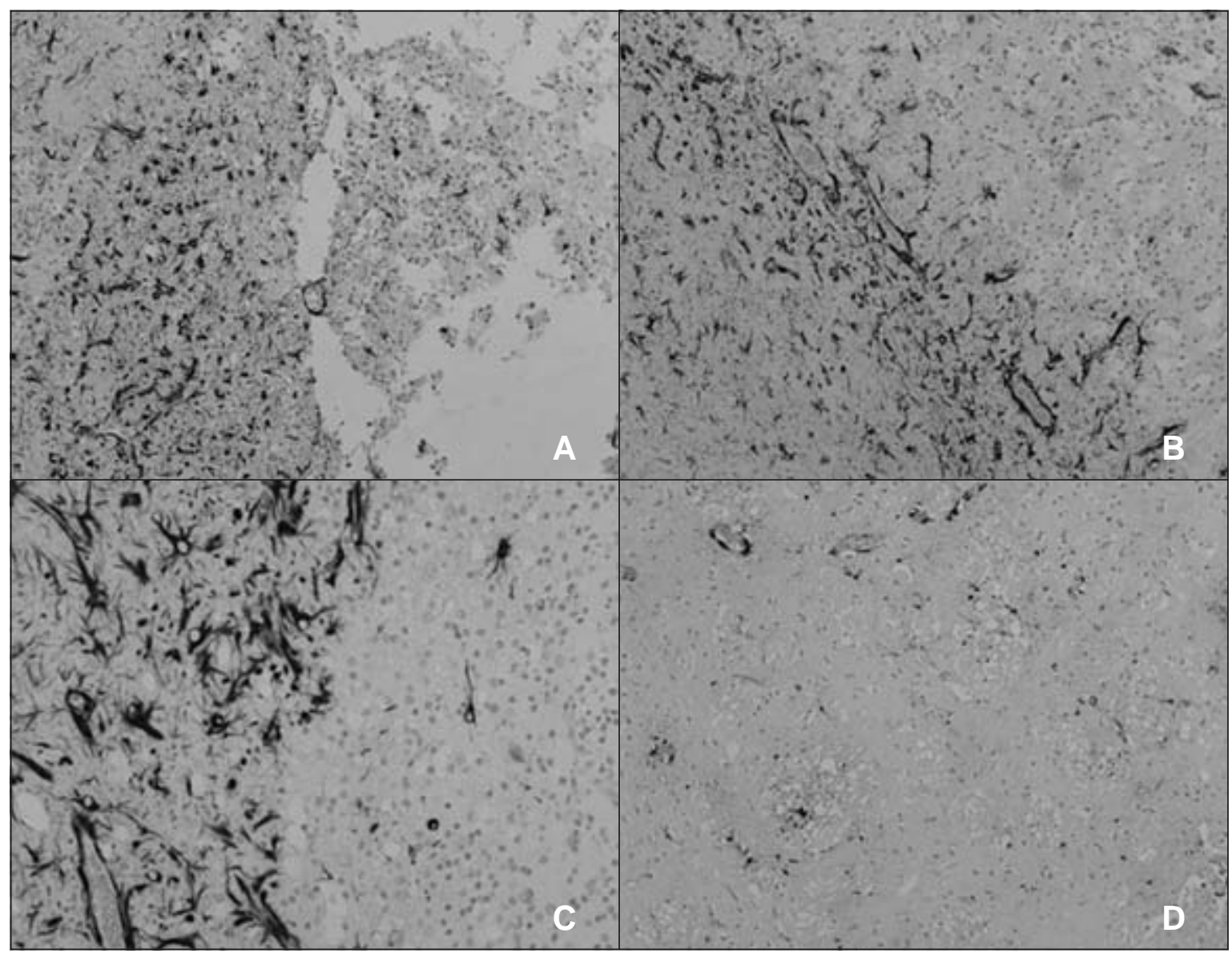

Figure 2: GFAP immunostaining at various conditions after MCAO. A,B,C and D represent Group 1,2,3 and 4 respectively. Reactive peri-infarct astrocytosis in Group 2 and 3 was prominent. However, the reactive peri-infarct astrocytosis in Group 4 was sparse, which means reactive astrocytosis can be affected by the exercise intensity.

To determine whether proliferation of astrocyte was associated with neurological recovery, we calculated the correlations between the thickness of the reactive astrocyte layers and the associated results on the neurological examination $(\mathrm{n}=39)$. Our result indicated a significant negative correlation $(\mathrm{r}$ $=-0.648 ; \mathrm{p}<0.01)($ Figure 4$)$.

\section{Discussion}

Our study of recovery from induced ischemic stroke in rats has two major findings. First, based on scores of neurological tests and the volumes of regions affected by cerebral infarction, early initiation of mild to moderate exercise is associated with better recovery. Second, the reactive astrocytotis around cerebral ischemia varied depending on exercise intensity, which had significant correlations with neurological recovery.

The mechanisms of exercise-induced recovery from cerebral ischemia are not yet clear, but increased blood pressure caused by exercise may have a role. ${ }^{18}$ Increases in blood pressure cause more blood flow to the brain and result in reduced size of cerebral infarction. ${ }^{19}$ In addition, increased cerebral blood flow helps facilitate oxygenation of the brain. ${ }^{20}$ Moreover, other studies found that active exercise facilitates neurogenesis of the dentate gyrus ${ }^{21}$ and promotes angiogenesis of the motor cortex. ${ }^{22}$ A recent study reported that rats who exercised before induction of cerebral ischemia had higher density of capillary vessels compared with controls who did not exercise.$^{23} \mathrm{~A}$ recent clinical study showed that exercise helps induce endothelium-derived vasodilation and promotes the expression of nitric oxide synthetase from endothelial cells in favor of effective vasodilation. $^{24}$

Our study indicates that appropriate exercise intensity can help neurological recovery from an induced stroke. In particular, our results showed that rats subjected to mild- or moderateintensity exercise had more significant recovery compared with controls that did not exercise and compared with rats subjected to severe-intensity exercise. Two previous reports of rats indicated that early induction of strenuous exercise may delay functional recovery following induced cerebral ischemia. ${ }^{10,11}$ The mechanism of this effect is unclear. Increased body temperature can cause neurological injury. ${ }^{25}$ So we suggest that intense exercise-induced increases in body temperature may adversely affect recovery from cerebral ischemia by a similar 
Table 1: Changes in neurological examination scores over time following MCAO

\begin{tabular}{lllll}
\hline & \multicolumn{3}{c}{ Group } \\
\cline { 2 - 4 } & $1(\mathrm{n}=9)$ & $2(\mathrm{n}=9)$ & $3(\mathrm{n}=10)$ & $4(\mathrm{n}=10)$ \\
\hline & & & & \\
Post-infarct 1 day & $2.8 \pm 0.4$ & $2.5 \pm 0.5$ & $2.4 \pm 0.7$ & $2.5 \pm 0.7$ \\
Post-infarct 4 days & $2.1 \pm 0.7$ & $2.0 \pm 0.9$ & $2.3 \pm 0.7$ & $2.1 \pm 0.8$ \\
Post-infarct 7 days & $2.1 \pm 0.3$ & $1.0 \pm 0.5^{*}$ & $1.2 \pm 0.4^{*}$ & $1.7 \pm 0.8$ \\
Post-infarct 10 days & $2.3 \pm 0.6$ & $1.0 \pm 0.8$ & $0.5 \pm 0.6^{*}$ & $1.3 \pm 0.5$ \\
Post-infarct 14 days & $2.3 \pm 0.6$ & $0.7 \pm 0.5^{*}$ & $0.3 \pm 0.5^{*}$ & $1.5 \pm 0.6$ \\
\hline
\end{tabular}

Group 1 rats that did not exercise; Group 2 rats that exercised at mild intensity; Group 3 rats that exercised at moderate intensity; Group 4 rats that exercised at severe intensity. Values are expressed as mean $\pm \mathrm{SD}$. ${ }^{*} \mathrm{P}<0.05$ versus Group 1.

mechanism. At the cellular level, intense stress and exercise are known to activate secretion of glucocorticoids, ${ }^{26}$ and endogenous glucocorticoid contributes to the basal level of brain injury resulting from cerebral ischemia. ${ }^{27}$ This may underlie the adverse effects of intense exercise that we observed. Intense exercise also inhibits the expression of Bcl-2 (a protein critical to apoptosis) and this may have a role in the poor recovery following intense exercise. ${ }^{28}$ In the early phase of cerebral ischemia, cells around cerebral infarction regions tend to react more sensitively to excitatory transmitters. Thus, early induction of intense exercise following a stroke may cause excessive secretion of excitatory neurotransmitters, including glutamate or catecholamine, 29 more nerve impulses induced by N-methyl-Daspartate (NMDA) receptor, and lower gamma-aminobutyric acid (GABA) -induced inhibitive reactions. ${ }^{30}$

Numerous previous studies have reported that recovery from morbid conditions depends on exercise intensity. For example, a study that used white hypertensive rats showed that low-intensity exercise was better than high-intensity exercise at reducing cardiac output and blood pressure. ${ }^{31}$ Ischemic heart disease and hypoxemic skeletal muscle activates AMP-activated protein kinase (AMPK) and intense exercise causes more cardiac AMPK

Table 2: Infarct volume and thickness of the reactive peri-infarct astrocytosis following MCAO

\begin{tabular}{|c|c|c|c|c|c|c|}
\hline \multicolumn{4}{|c|}{ Infarct Volume $(\%)$} & \multicolumn{3}{|c|}{ Astrocyte Thickness (mm) } \\
\hline Group & 1 day & 1 week & 2 weeks & 1 day & 1 week & 2 weeks \\
\hline \multirow[t]{2}{*}{1} & $39.9 \pm 14.3$ & $37.6 \pm 21.8$ & $30.7 \pm 14.4$ & $1.02 \pm 0.12$ & $1.41 \pm 0.59$ & $0.84 \pm 0.30$ \\
\hline & $(n=9)$ & $(n=10)$ & $(n=5)$ & $(n=4)$ & $(n=4)$ & $(n=4)$ \\
\hline \multirow[t]{2}{*}{2} & & $20.4 \pm 17.9^{*}$ & $14.2 \pm 9.1$ & & $1.28 \pm 0.52$ & $1.29 \pm 0.23$ \\
\hline & & $(\mathrm{n}=9)$ & $(n=5)$ & & $(n=5)$ & $(n=4)$ \\
\hline \multirow[t]{2}{*}{3} & & $19.4 \pm 12.8^{*}$ & $19.4 \pm 5.5$ & & $1.25 \pm 0.61$ & $1.09 \pm 0.47$ \\
\hline & & $(n=10)$ & $(n=4)$ & & $(n=5)$ & $(n=6)$ \\
\hline \multirow[t]{2}{*}{4} & & $33.1 \pm 15.2$ & $30.4 \pm 12.8$ & & $0.56 \pm 0.19^{*}$ & $0.64 \pm 0.32$ \\
\hline & & $(n=10)$ & $(n=4)$ & & $(n=5)$ & $(n=6)$ \\
\hline
\end{tabular}

Values are expressed as mean \pm SD. *Significant different from Group 1 at one week $(\mathrm{p}<0.05)$. 


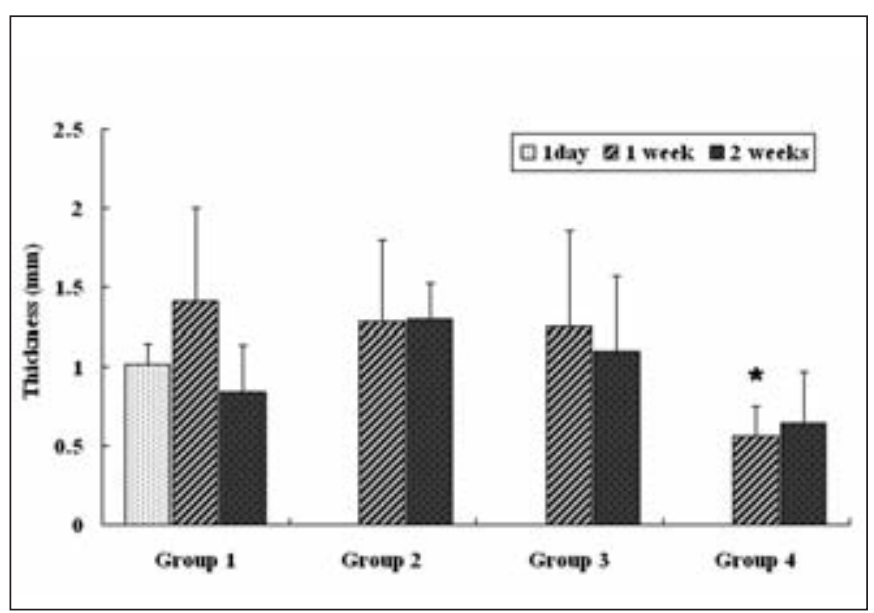

Figure 3: Thickness of the reactive peri-infarct astrocytosis ( $\mathrm{mm}$ ) after $M C A O$. *Significantly different $(p<0.05)$ from Group 1 at 1 week after MCAO.

activity. ${ }^{32}$ Another study showed that rats subjected to intense exercise suffered from more severe injury of hepatic cells. ${ }^{33}$ More recently, Kim et $\mathrm{al}^{34}$ reported that cell proliferation in the dentate gyrus of rats depends on the magnitude and duration of treadmill exercise, and that mild exercise was better than intense exercise. Our study is first to investigate the effect of exercise intensity on recovery from induced cerebral ischemia.

Our study also examined the effect of exercise intensity on astrocytes. Astrocytes are more active around regions of cerebral infarction after onset of cerebral ischemia, ${ }^{35}$ although the function of astrocytes in cerebral ischemia is unknown. It is possible that astrocyte reactions contribute to neurological recovery from cerebral infarction by secretion of neurotropic factors, activation of angiogenesis, and activation of neurogenesis. ${ }^{36}$ Another possibility is that astrocyte reactions accelerate secretion of glutamate and that this causes scarring around cerebral infarction regions, resulting in adverse neurological effects. ${ }^{37}$ It is known that gap junctions (intercellular structural connections in astrocytes) stay open during cerebral ischemia, and that substances that accelerate apoptosis move from dead cells into living cells, where they induce apoptosis. ${ }^{38}$ However, a recent study showed that the lack of connexin-43 (a modifier of gap junction) results in larger cerebral infarction regions, suggesting that gap junctions protect from cerebral ischemia. ${ }^{39}$

Our results clearly indicate that astrocyte reactions were negatively correlated with neurological recovery suggesting that the exercise-mediated recovery from cerebral ischemia affects astrocytes. In view of recent findings that astrocytes proliferate more actively when normal rats exercise, ${ }^{40}$ we suggest that exercise-induced astrocyte proliferation has positive effects on the regeneration of capillaries and thereby contributes to the regeneration of the blood-brain barrier and angiogenesis.

After onset of cerebral ischemia, neurons begin to regenerate around regions beneath the ventricle and the dentate gyrus of the hippocampus. ${ }^{41}$ Some reports have suggested that this regeneration is associated with immature astrocytes, ${ }^{42}$ and that

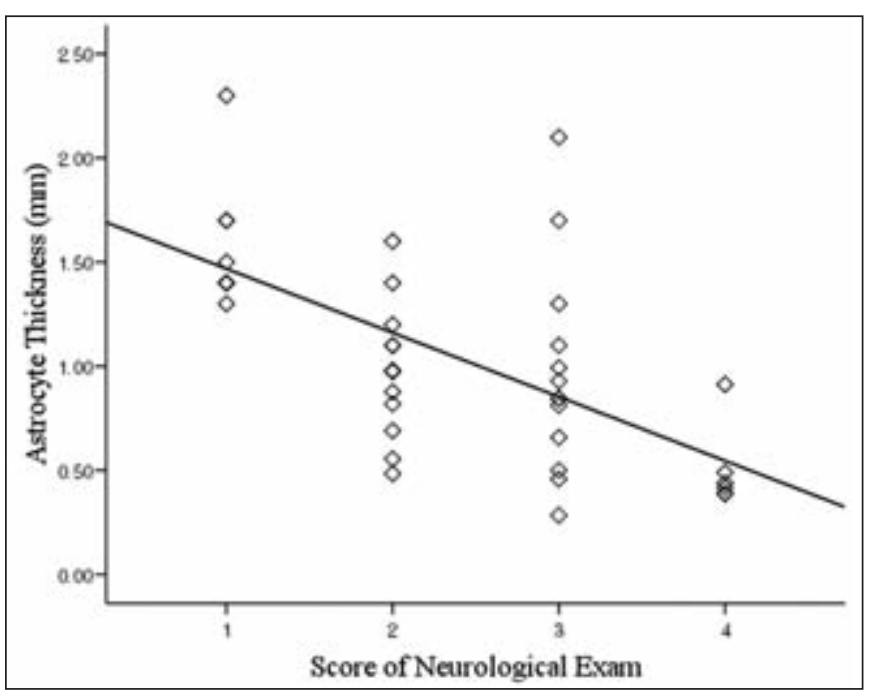

Figure 4: Correlation of thickness of the reactive astrocyte layer and score on the neurological examination. Abscissa, score of neurological examination; ordinate, thickness of the reactive astrocyte layer. Spearman correlation coefficient: $r=-0.648(p<0.01)$. Data from $24 \mathrm{~h}$ after cerebral artery occlusion were not included.

astrocytes induce neurogenesis of the stem cells of the hippocampus. ${ }^{43}$ Based on the finding that exercise accelerates neurogenesis of the dentate gyrus, ${ }^{34}$ it seems likely that astrocyte proliferation is increased with exercise and thereby aids neurological recovery following cerebral ischemia. In view of the aforementioned finding that connexin-43, which modifies the gap junctions of astrocytes, controls the migration of factors that accelerate penumbra cerebral ischemic apoptosis and reduce apoptosis-induced nerve injury, ${ }^{44}$ we propose that exerciseinduced astrocyte proliferation likely restrains apoptosis and thereby has positive effects on neurological recovery.

There were several limitations in our study. First, we determined exercise intensity by calculating percentage of maximum exercise velocity which rats can run. It would certainly strengthen our paper if we use objective measure to quantify varying degree of exercise intensity, such as oxygen consumption, heart rate etc. Second, an important limitation of this study was the small sample size. Nevertheless, we were able to show benefits of mild to moderate-intensity exercise in infarct volume and neurological score. This trend of changes we observed warrants further study with a larger sample size to allow for a more discerning statistical analysis. Third, all rats were not familiarized with the treadmill training on a treadmill before MCAO. They only performed familiarized exercise 24 hours after MCAO.

In conclusion, when rats undergo MCAO, mild- to moderateintensity exercise improves neurological function and reduces the volume of cerebral infarct regions. Intense exercise has similar effects as no exercise. Hence, control of exercise intensity is critical for recovery from induced cerebral ischemia. The mechanism of these effects should be addressed by cellular and molecular biology studies of cerebral apoptosis, angiogenesis, and the expression of neurotropic factors. 


\section{REFERENCES}

1. Lambo TA. Stroke--a worldwide health problem. Adv Neurol. 1979;25:1-3.

2. Ernst E. A review of stroke rehabilitation and physiotherapy. Stroke. 1990;21:1081-5.

3. Stummer W, Weber K, Tranmer B, Baethmann A, Kempski O. Reduced mortality and brain damage after locomotor activity in gerbil forebrain ischemia. Stroke. 1994;25:1862-9.

4. Ding Y, Li J, Lai Q, Rafols JA, Luan X, Clark J, et al. Motor balance and coordination training enhances functional outcome in rat with transient middle cerebral artery occlusion. Neuroscience. 2004;123:667-74.

5. Kim MW, Bang MS, Han TR, Ko YJ, Yoon BW, Kim JH, et al. Exercise increased BDNF and trkB in the contralateral hemisphere of the ischemic rat brain. Brain Res. 2005;1052: 16-21.

6. Richards CL, Malouin F, Wood-Dauphinee S, Williams JI, Bouchard JP, Brunet D. Task-specific physical therapy for optimization of gait recovery in acute stroke patients. Arch Phys Med Rehabil. 1993;74:612-20.

7. Hesse S, Bertelt C, Jahnke MT, Schaffrin A, Baake P, Malezic M, et al. Treadmill training with partial body weight support compared with physiotherapy in nonambulatory hemiparetic patients. Stroke. 1995;26:976-81

8. Johansson BB, Ohlsson AL. Environment, social interaction, and physical activity as determinants of functional outcome after cerebral infarction in the rat. Exp Neurol. 1996;139:322-7.

9. Ohlsson AL, Johansson BB. Environment influences functional outcome of cerebral infarction in rats. Stroke. 1995;26:644-9.

10. Humm JL, Kozlowski DA, James DC, Gotts JE, Schallert T. Usedependent exacerbation of brain damage occurs during an early post-lesion vulnerable period. Brain Res. 1998;783:286-92.

11. Kozlowski DA, James DC, Schallert T. Use-dependent exaggeration of neuronal injury after unilateral sensorimotor cortex lesions. J Neurosci. 1996;16:4776-86.

12. Yang YR, Wang RY, Wang PS, Yu SM. Treadmill training effects on neurological outcome after middle cerebral artery occlusion in rats. Can J Neurol Sci. 2003;30:252-8.

13. Yang YR, Wang RY, Wang PS. Early and late treadmill training after focal brain ischemia in rats. Neurosci Lett. 2003;339:91-4.

14. Longa EZ, Weinstein PR, Carlson S, Cummins R. Reversible middle cerebral artery occlusion without craniectomy in rats. Stroke. 1989;20:84-91.

15. Garcia JH, Wagner S, Liu KF, Hu XJ. Neurological deficit and extent of neuronal necrosis attributable to middle cerebral artery occlusion in rats. Statistical validation. Stroke. 1995;26:627-34; discussion 35.

16. Menzies SA, Hoff JT, Betz AL. Middle cerebral artery occlusion in rats: a neurological and pathological evaluation of a reproducible model. Neurosurgery. 1992;31:100-6; discussion 6-7.

17. Swanson RA, Morton MT, Tsao-Wu G, Savalos RA, Davidson C, Sharp FR. A semiautomated method for measuring brain infarct volume. J Cereb Blood Flow Metab. 1990;10:290-3.

18. Berne RM, Levy MN. Physiology. 3rd ed. St. Louis: Mosby Year Book; 1993.

19. Auer RN. Non-pharmacologic (physiologic) neuroprotection in the treatment of brain ischemia. Ann N Y Acad Sci. 2001;939: 271-82.

20. Ide K, Horn A, Secher NH. Cerebral metabolic response to submaximal exercise. J Appl Physiol. 1999;87:1604-8.

21. van Praag H, Kempermann G, Gage FH. Running increases cell proliferation and neurogenesis in the adult mouse dentate gyrus. Nat Neurosci. 1999;2:266-70.

22. Kleim JA, Cooper NR, VandenBerg PM. Exercise induces angiogenesis but does not alter movement representations within rat motor cortex. Brain Res. 2002;934:1-6.

23. Ding Y, Li J, Luan X, Ding YH, Lai Q, Rafols JA, et al. Exercise pre-conditioning reduces brain damage in ischemic rats that may be associated with regional angiogenesis and cellular overexpression of neurotrophin. Neuroscience. 2004;124: 583-91.
24. Hambrecht R, Wolf A, Gielen S, Linke A, Hofer J, Erbs S, et al. Effect of exercise on coronary endothelial function in patients with coronary artery disease. N Engl J Med. 2000;342:454-60.

25. Ginsberg MD, Sternau LL, Globus MY, Dietrich WD, Busto R. Therapeutic modulation of brain temperature: relevance to ischemic brain injury. Cerebrovasc Brain Metab Rev. 1992;4:189-225.

26. Borer KT, Bestervelt LL, Mannheim M, Brosamer MB, Thompson M, Swamy U, et al. Stimulation by voluntary exercise of adrenal glucocorticoid secretion in mature female hamsters. Physiol Behav. 1992;51:713-8.

27. Smith-Swintosky VL, Pettigrew LC, Sapolsky RM, Phares C, Craddock SD, Brooke SM, et al. Metyrapone, an inhibitor of glucocorticoid production, reduces brain injury induced by focal and global ischemia and seizures. J Cereb Blood Flow Metab. 1996;16:585-98.

28. DeVries AC, Joh HD, Bernard O, Hattori K, Hurn PD, Traystman RJ, et al. Social stress exacerbates stroke outcome by suppressing Bcl-2 expression. Proc Natl Acad Sci USA. 2001; 98:11824-8.

29. Vanderwolf $\mathrm{CH}$, Cain DP. The behavioral neurobiology of learning and memory: a conceptual reorientation. Brain Res Brain Res Rev. 1994;19:264-97.

30. Qu M, Mittmann T, Luhmann HJ, Schleicher A, Zilles K. Longterm changes of ionotropic glutamate and GABA receptors after unilateral permanent focal cerebral ischemia in the mouse brain. Neuroscience. 1998;85:29-43.

31. Veras-Silva AS, Mattos KC, Gava NS, Brum PC, Negrao CE, Krieger EM. Low-intensity exercise training decreases cardiac output and hypertension in spontaneously hypertensive rats. Am J Physiol. 1997;273:H2627-31.

32. Coven DL, Hu X, Cong L, Bergeron R, Shulman GI, Hardie DG, et al. Physiological role of AMP-activated protein kinase in the heart: graded activation during exercise. Am J Physiol Endocrinol Metab. 2003;285:E629-36.

33. Kinoshita S, Yano H, Tsuji E. An increase in damaged hepatocytes in rats after high intensity exercise. Acta Physiol Scand. 2003; 178:225-30.

34. Kim YP, Kim HB, Jang MH, Lim BV, Kim YJ, Kim H, et al. Magnitude- and time-dependence of the effect of treadmill exercise on cell proliferation in the dentate gyrus of rats. Int $\mathrm{J}$ Sports Med. 2003;24:114-7.

35. Mabuchi T, Kitagawa K, Ohtsuki T, Kuwabara K, Yagita Y, Yanagihara $\mathrm{T}$, et al. Contribution of microglia/macrophages to expansion of infarction and response of oligodendrocytes after focal cerebral ischemia in rats. Stroke. 2000;31:1735-43.

36. Liberto CM, Albrecht PJ, Herx LM, Yong VW, Levison SW. Proregenerative properties of cytokine-activated astrocytes. J Neurochem. 2004;89:1092-100.

37. Aschner M. Astrocytic functions and physiological reactions to injury: the potential to induce and/or exacerbate neuronal dysfunction--a forum position paper. Neurotoxicology. 1998;19:7-17; discussion 37-8.

38. Lin JH, Weigel H, Cotrina ML, Liu S, Bueno E, Hansen AJ, et al. Gap-junction-mediated propagation and amplification of cell injury. Nat Neurosci. 1998;1:494-500.

39. Siushansian R, Bechberger JF, Cechetto DF, Hachinski VC, Naus CC. Connexin 43 null mutation increases infarct size after stroke. J Comp Neurol. 2001;440:387-94.

40. Li J, Ding YH, Rafols JA, Lai Q, McAllister JP, 2nd, Ding Y. Increased astrocyte proliferation in rats after running exercise. Neurosci Lett. 2005;386:160-4.

41. Komitova M, Perfilieva E, Mattsson B, Eriksson PS, Johansson BB. Effects of cortical ischemia and postischemic environmental enrichment on hippocampal cell genesis and differentiation in the adult rat. J Cereb Blood Flow Metab. 2002;22:852-60.

42. Alonso G. Proliferation of progenitor cells in the adult rat brain correlates with the presence of vimentin-expressing astrocytes. Glia. 2001;34:253-66.

43. Song H, Stevens CF, Gage FH. Astroglia induce neurogenesis from adult neural stem cells. Nature. 2002;417:39-44.

44. Nakase T, Fushiki S, Naus CC. Astrocytic gap junctions composed of connexin 43 reduce apoptotic neuronal damage in cerebral ischemia. Stroke. 2003;34:1987-93. 